\title{
Experimental evaluation of different strengthening techniques of traditional timber connections
}

\section{Introduction}

The most common joint in existing timber roof structures is the "birdsmouth joint with a single tooth", although geometry varies with joint location in the truss, and the joint bearing capacity is function of skew angle, notch depth and length of the toe. The load transmission relies on direct contact and friction between facing surfaces. Metal ties or fasteners are not mean to transmit forces directly; they are mainly used for positioning and maintaining the functionality of the joint in adverse or unpredictable conditions.

Common timber roof structures are usually modelled with perfect hinges at the extremities of each element. However, these joints offer a significant moment resistance and may be better classified as semi-rigid [1]. The lack of practical though realistic models for the joints in old traditional timber structures generally leads to very conservative retrofits and upgrades to satisfy new safety and serviceability requirements. Moreover, the misunderstanding of the global behavior of traditional roof trusses can result in unacceptable stresses in the members as a consequence of inappropriate joint strengthening (in terms of stiffening) [2]. Joint strengthening can be done in a number of possible ways: from simple replacement or addition of fasteners, to the use of metal plates, glued composites or even full injection with fluid adhesives. Each solution presents unique consequences in terms of the joint final strength, stiffness and ductility. An international research program, including a PhD program [3], has been developed by the authors with the purpose of investigating the monotonic and cyclic behaviors of traditional timber connections and identifying and evaluating suitable strengthening techniques using metal devices.

The research aims to analyze Portuguese traditional timber connections and in its preparation and development all observations and conclusions obtained in previous works of the team research were taken into account ([4], [1] and [2]).

\section{Experimental Campaign \}}

An experimental research was carried out at the Laboratory of Structures of the University of Minho (Portugal), including monotonic and cyclic tests of full-scale traditional timber connections. A series of monotonic and cyclic tests on unstrengthened specimens was performed in order to study the primary behavior characteristics of the connection, as well as its sensitivity to a few parameters. Subsequently, connections strengthened with basic metal devices were tested under monotonic and cyclic loading. The purpose of these tests was to uncover any advantages and deficiencies in the behavior of the connection and the device itself, as well as to determine a need for different types of strengthening. Tests on assembled 
connections were preceded by accurate material characterization, determining the mechanical properties of the timber elements used for all full-scale models.

Table 1 summarises the most important tests on traditional timber connections performed in this experimental analysis. Because of their frequency in the preliminary roofs survey undertaken, two skew angles were adopted for the connections: $30^{\circ}$ and $60^{\circ}$. Two compression levels of the rafter were adopted, 1.4 MPa and $2.5 \mathrm{MPa}$, in accordance with the Service and Ultimate Limit States, respectively, defined for common Portuguese timber roof structures (see [5]). For all types of connection evaluated, nine tests were performed: 6 monotonic, being 3 in each loading direction (positive and negative), and three more under cyclic loading. Strengthened connections were studied only under a compression level in the rafter of $1.4 \mathrm{MPa}$ corresponding to the Service Limit State conditions. Four strengthening techniques were initially selected (stirrups, internal bolt, binding strip and tension ties) but, during the experimental campaign, the binding strip technique was abandoned.

In addition, others tests were carried out, mostly resulting from attempts to analyse other materials (carbon fibre reinforced polymers) or different ways of using some of the strengthening techniques studied (in particular, stirrups nailed, bolts with a smaller diameter and two slender bolts instead of one with $12 \mathrm{~mm}$ of diameter). More details about those tests and their results can be obtained in [6] and [7], respectively.

\subsection{Wood properties}

A mechanical characterization of the Maritime pine timber (Pinus pinaster Ait.) used in the connections was performed. In the carpentry shops where the connections were fabricated, all wood elements used were visually graded as belonging to quality class $\mathrm{E}$ according to the Portuguese National Standard [8]. Quality class E corresponds to a strength class C18 according to [9]. Then, on samples collected during the fabrication of the connections, mechanical tests (bending, compression parallel and perpendicular to the grain) were performed in laboratory following [10]. For all tests, the failure time was register and the moisture content of each specimen was measure with an electronic thermo hygrometer for wood.

Comparing the wood characterization tests results obtained with the values reported by [11], for Pinus pinaster, Ait. of quality class E, (Table 2) it can be concluded that: (1) the tests results obtained for the bending and compression parallel to the grain strengths $\left(f_{\mathrm{m}}\right.$, and $\left.f_{\mathrm{c}, 0}\right)$ above the values suggested in all cases; (2) all tests results of the compression perpendicular to the grain strength $\left(f_{\mathrm{c}, 90}\right)$ were lower than the value suggested; (3) the test result of the modulus of elasticity in bending, mean and characteristic values, are very similar to the reported in bibliography.

\subsection{Test setup and instrumentation}


The arrangement allows independent control of two hydraulic jacks (Figure 1). One jack, aligned with the rafter, induced constant compression throughout the test. The other, a double-acting jack, positioned above the center of the connection, applied a transversal force, with a programmed load cycle, and generated a moment at the connection. Force $(F)$ versus displacement $(d)$ curves were measured. The two jacks have a maximum loading capacity of 50 $\mathrm{kN}$ and $100 \mathrm{kN}$ and a maximum stroke of $160 \mathrm{~mm}$ and $50 \mathrm{~mm}$, respectively. Type and location of instrumental channels, including load cells and linear variable differential transformers (LVDTs), are shown in Figure 1.

Tests were performed under displacement control for the typical birdsmouth connection skew angle of $30^{\circ}$ and $60^{\circ}$. For all the specimens, the cross sections of the elements were $80 \times 220 \mathrm{~mm}^{2}$, the notch depth was $45 \mathrm{~mm}$ and the notch length was $422 \mathrm{~mm}$ as represented in Figure 2.

The first step of the loading procedures in both the monotonic and cyclic tests was the application of an axial compression force on the rafter, which was kept constant during the test. In the subsequent loading steps, a transversal force $(F)$ was employed, acting perpendicular to the rafter axis.

When the skew angle increased, it was defined as the positive direction and when the skew angle decreased, it was defined as the negative direction. Monotonic tests were performed to determine the elastic behavior, in particular, the apparent elastic limit displacement $d_{e}{ }^{+}$and $d_{e}$. Under displacement control at channel 00, a maximum displacement value of $50 \mathrm{~mm}$ was imposed under a displacement rate of $0.028 \mathrm{~mm} / \mathrm{s}$ and $0.18 \mathrm{~mm} / \mathrm{s}$ in the case of connections with a skew angle of $30^{\circ}$ and $60^{\circ}$, respectively.

\subsection{Cyclic test procedure}

Full-scale connections, similar to the specimens of monotonic loading, were tested with a quasi static cyclic loading. In particular, the test program included one cycle in the range $\left[0.25 \mathrm{~d}_{\mathrm{e}}{ }^{+}\right.$; $0.25 \mathrm{~d}_{\mathrm{e}}$ ]; one cycle in the range $\left[0.50 \mathrm{~d}_{\mathrm{e}}^{+} ; 0.50 \mathrm{~d}_{\mathrm{e}}\right]$; three cycles in the range $\left[0.75 \mathrm{de}_{\mathrm{e}}^{+} ; 0.75 \mathrm{~d}_{\mathrm{e}}{ }^{-}\right.$ ]\$; three cycles in the range $\left[\mathrm{nde}_{\mathrm{e}}{ }^{+} ; n d_{\mathrm{e}}\right]$ ] until connections failure. The values used for the elastic limit displacements, for both positive $\left(d_{e}{ }^{+}\right)$and negative $\left(d_{e}{ }^{-}\right)$directions, were based on results obtained in the monotonic tests.

However, there is some difference between the two types of connection $\left(30^{\circ}\right.$ and $60^{\circ}$ skew angle, respectively). While in the first case, asymmetric values were adopted for the apparent elastic limit displacements, $d_{e}$, and $n$ assumes $0,1,2,3,4,5, \ldots$, in the second, an average value for $d_{e}$ was adopted, obtained from the mean value in each direction, and $n$ assumes 1,2 , $4,6, \ldots$. The first sequence is in accordance with [12] and the second agrees with [13]. The first phase of this experimental campaign is based in previous works ([4] and [1]) and with the evolution of the work, some improvements were implemented. 


\section{Strengthening techniques studied}

The four basic types of intervention considered in this study are modern implementations of traditional strengthening or construction techniques: the stirrups, the internal bolt, the binding strip and the tension ties (Figure 3).

Metal stirrups placed in pairs at two opposite sides of the connection were very popular in the past and are still considered adequate and frequently adopted. The effect of the large increase of the in-plane stiffness connection is particularly important and should be studied. In this study, each stirrup was composed of two steel plates welded in a V-shape (Figure 3a). Each prong was $50 \mathrm{~mm}$ wide and $5 \mathrm{~mm}$ thick. They were parallel to the rafter or to the tie beam, and bolted to it with seven bolts of $10 \mathrm{~mm}$ diameter.

The use of an internal steel rod, of $12 \mathrm{~mm}$ diameter, was also considered (Figure $3 \mathrm{~b}$ ). The rod was fixed by a nut at both ends and secured by using a special rectangular-shape washer (70x30 $\mathrm{mm}^{2}$ and $5 \mathrm{~mm}$ thick). The rod was located at the mid-connection and normal to the axis of the tie beam. A suitable seat area was formed in the rafter for accommodating it, thus allowing perfect contact between surfaces.

Metal binding strips, considered obsolete today, were very frequently adopted in 19th century roof structures, particularly to strengthen the rafter and tie beam connection in configurations that had skew angles typically of $30^{\circ}$, see [5]. Two updated versions of this layout were considered: i) (Figure 3c) the connection was bound with a steel ribbon, $50 \mathrm{~mm}$ wide and $5 \mathrm{~mm}$ thick, located at mid-connection, normal to the tie beam (series BSi); and ii) the connection was bound with two steel plates located in the bottom surface of the tie beam and upper surface of the rafter, with the dimensions of $40 \times 159 \mathrm{~mm}^{2}$ and $10 \mathrm{~mm}$ thick, tightened through two rods of $12 \mathrm{~mm}$ (TTi) (Figure 3d). The rods, having a nut at both ends, located at mid-connection, normal to the tie beam, enabled full control in the tightening force during the strengthening lifetime. The first version, called rigid binding strip, was only used for $30^{\circ}$ skew angle case.

\section{Efficiency evaluation of the strengthening techniques}

\subsection{Binding strip}

The binding strip was analyzed only in the case of $30^{\circ}$ skew angle, and corresponds to a first phase of the experimental campaign carried out. The experimental results show that this strengthening technique is capable of improving the connection behavior, in terms of resistance, ductility and dissipation of energy, though its implementation, especially in situ, is extremely difficult. The rigid steel ribbon that materializes this binding strip is only suitable for new applications. Despite this limitation, the experimental results obtained can be of practical interest. 
Figure 4 shows the experimental force-displacement curves obtained in the case of the connections strengthened with a rigid binding strip, under monotonic loading for $30^{\circ}$ skew angle.

The resistance of the strengthened connections is considerable $(\approx 19 \mathrm{kN})$ and seems to be independent from the monotonic loading direction. Changing the loading direction, doesn't affect stiffness either to a significant extend. Table 3 presents the main results obtained from the monotonic tests on strengthened connections with binding strip.

The strengthened connections with binding strip are strong, but the damages induced in the timber elements during the tests are important (Figure 5). The tie effect provided by the binding strip is so high that, under monotonic loading in the positive direction, the bottom part of the rafter does not move and the imposed displacement history only affects the top part. In consequence, major bending stresses are induced in the rafter. In the other loading direction, negative or decreasing the skew angle, the damages are essentially located in the tie beam member, in particular due to local compression perpendicular to the grain.

A quasi-static history of loading and unloading was applied under a displacement rate of 0.224 $\mathrm{mm} / \mathrm{s}$ using the apparent elastic displacement limit values of $d_{\max }{ }^{+}=4.5 \mathrm{~mm}$ and $d_{\max }{ }^{-}=7 \mathrm{~mm}$ obtained in the monotonic tests. The experimental force-displacement loops obtained, for the strengthened connections with binding strip tested under cyclic loading are presented in Figure 6.

In agreement with the monotonic tests, the loops obtained in the cyclic tests are asymmetric. Although, under negative loading the force-displacement curves are linear elastic, more dependent on the friction conditions, when subjected to positive loading, the force-displacement curve presents a non-linear development. After the first cycles with no dissipation of energy, wide loops are exhibited for the negative loading while the ones obtained in the positive loading are thin. Therefore, it can be concluded that dissipation of energy only occurs in the negative field. Nevertheless, the dissipation of energy is considerable. The maximum load values achieved in each loading direction are similar and the value calculated for the equivalent viscous damping ratio is very consistent $(\mathrm{CoV}=0.07)$.

\subsection{Stirrup}

The direction of the monotonic loading seems to be of minor influence in the behavior of connections strengthened with stirups (Figure 7). The most important difference detected is the variation of the stiffness with the loading direction in the case of $30^{\circ}$ skew angle connections. On the other hand, the skew angle is associated with: a) the strength and the stiffness decrease with the increase of the skew angle and, b) increase in the apparent elastic displacement limit, reached in the positive direction, with the enlargement of the skew angle from $30^{\circ}$ to $60^{\circ}$. The maximum force value increases throughout the entire test, which indicates that perhaps, if the 
tests were extended, the maximum force value could increase. Table 4 summarises the monotonic tests results obtained for strengthened connections with stirrups.

By the end of the tests, different damages were detected (see Figure 8). In the negative direction, no damage was observed with exception to the local compression in the posterior part of the notch, while, in the positive direction, the most common damage was failure of the stirrup itself.

Based on the monotonic tests results for the apparent elastic displacement limit $\left(d_{e}\right)$, the values of $\mathrm{d}_{\mathrm{e}}{ }^{+}=\mathrm{d}_{\mathrm{e}}{ }^{-}=5.70 \mathrm{~mm}$ and $\mathrm{d}_{\mathrm{e}}{ }^{+}=\mathrm{d}_{\mathrm{e}}{ }^{-}=13.61 \mathrm{~mm}$ were assumed for the $30^{\circ}$ and $60^{\circ}$ skew angle connections, respectively, for the imposed displacement time history used in the cyclic tests. A quasi-static history of loading and unloading was applied under a displacement rate of 0.224 $\mathrm{mm} / \mathrm{s}$ and $0.18 \mathrm{~mm} / \mathrm{s}$ in the case of $30^{\circ}$ and $60^{\circ}$ skew angle connections, respectively. The force-displacement loops obtained, for the strengthened connections with stirrups tested under cyclic loading, are presented in Figure 9.

The most important conclusion that can be drawn from Figure 9 is the ability of these strengthened connections, under cyclic loading, to dissipate energy in both loading directions as shown by the wide loops. The maximum force values and displacement for both loading directions are quite similar. As expected, and in agreement with the results obtained in the monotonic tests, a higher skew angle results in less energy dissipated and lower connection strength.

\subsection{Bolt}

The experimental force-displacement curves obtained in the case of the connections strengthened with bolt, under monotonic loading for $30^{\circ}$ and $60^{\circ}$ skew angles, show a full nonlinear development with high ductility (Figure 10).

The three specimens considered for each variable show very consistent results, only diverging in the maximum force value $\left(\mathrm{F}_{\max }\right)$, in particular in the case of $30^{\circ}$ skew angle connections under monotonic positive loading. The higher is the skew angle, the smaller are the strength and the stiffness achieved by the strengthened connection. In the case of a skew angle equal to $60^{\circ}$, the direction of the loading does not seem to have influence in the connection strength, despite it affects the stiffness and the apparent elastic displacement limit. Despite the asymmetry observed in the values of the apparent displacement limit and in the maximum force reached, for a $30^{\circ}$ skew angle, the stiffness does not depend on the loading direction. Table 5 summarises the monotonic tests results obtained for strengthened connections with bolts.

The ductility provided by the strengthening is optimized when the bolt is aligned with the force caused by the external load applied. The best results are achieved for $30^{\circ}$ skew angle under monotonic loading in the negative direction (closing the skew angle), as this corresponds to the case of higher axial tension in the bolt. The higher is the axial tension in the bolt, the higher is 
the strength and more ductility is obtained. When opening the skew angle, the bolt is tensioned but is also subjected to bending, in particular in the case of $30^{\circ}$ skew angle.

In the negative direction, apart from the action of the bolt, that is firstly subjected to tension and then under bending, when increasing the imposed displacement another resistant mechanism is revealed: the local compression perpendicular to the grain in the tie beam element (Figure 11). A local compression of wood, detected in the backside of the connection already in unstrengthened connections, is enhanced here by strengthening. This local effect is responsible for a plastic phase in the force-displacement response of these connections.

The apparent elastic displacement limit values of $d_{e}{ }^{+}=5 \mathrm{~mm}$ and $d_{e}{ }^{-}=-8.5 \mathrm{~mm}$ and $d_{e}{ }^{+}=d_{e}{ }^{-}=$ $8.15 \mathrm{~mm}$ were assumed for the $30^{\circ}$ and $60^{\circ}$ skew angle connections, respectively, for the imposed displacement time history that represents the cyclic tests.

A quasi-static history of loading and unloading was applied at a rate of $0.224 \mathrm{~mm} / \mathrm{s}$ and $0.18 \mathrm{~mm} / \mathrm{s}$ in the case of $30^{\circ}$ and $60^{\circ}$ skew angle connections, respectively. The experimental force-displacement loops obtained, for the strengthened connections with bolts tested under cyclic loading, are presented in Figure 12.

The force-displacement loops obtained for the strengthened connections with bolt under the cyclic loading tests are asymmetric, in particular in the case of $30^{\circ}$ skew angle connections. The force and displacement values are higher for the negative loading and the main dissipation of energy happens there. By increasing the skew angle from $30^{\circ}$ to $60^{\circ}$ the strength of the strengthened connections is reduced. The pinching effect observed in the force-displacement loops is quite higher in the case of the $30^{\circ}$ skew angle connection. The higher is the skew angle, the smaller are the strength obtained and the energy dissipated.

\subsection{Tension ties}

The experimental force-displacement curves obtained in the case of the connections strengthened with tension ties, under monotonic loading for $30^{\circ}$ and $60^{\circ}$ skew angles, show a full non-linear development with high ductility (see Figure 13).

All results are consistent and the response is only slightly affected by the skew angle value and the monotonic loading direction. Strength, stiffness and the shape of the force-displacement curves are quite constant, except for the case where the skew angle is $30^{\circ}$ and the strengthened connections are subjected to monotonic loading in the negative direction. In this loading direction, in the case of a $60^{\circ}$ skew angle, a significant plastic phase is observed in the force-displacement experimental curves obtained. Table 6 summarises the main results of the monotonic tests of strengthened connections with tension ties where these observations can be seen.

Only the $60^{\circ}$ skew angle strengthened connections with tension ties showed visible damage. That local damage is different for each monotonic loading direction. When opening the skew 
angle, local compression of the front of the notch is observed (Figure 14a). In the other direction, local compression perpendicular to the grain is detected in the backside of the connection (Figure 14b).

From the monotonic tests results, apparent elastic displacement limit values equal to $d_{e}{ }^{+}=d_{e}{ }^{-}=$ $4.90 \mathrm{~mm}$ and $\mathrm{d}_{\mathrm{e}}{ }^{+}=\mathrm{d}_{\mathrm{e}}{ }^{-}=8.20 \mathrm{~mm}$ were assumed for the $30^{\circ}$ and $60^{\circ}$ skew angle connections, respectively. Those values were used in the imposed displacement time history applied in the cyclic tests. A quasi-static history of loading and unloading was applied at a velocity of 0.18 $\mathrm{mm} / \mathrm{s}$. The experimental force-displacement loops obtained for the strengthened connections with tension ties tested under cyclic loading are presented in Figure 15.

Despite the asymmetry exhibited by the monotonic tests results, the $30^{\circ}$ skew angle strengthened connections present quite symmetric loops in the cyclic tests. On the contrary, the cyclic tests results of $60^{\circ}$ skew angle strengthened connections are quite asymmetric. The loop development is different for the negative and the positive loading directions. In the negative loading direction, a plastic behavior is observed which results in a reduction of connections strength, in comparison with the positive loading direction. The maximum load values achieved are quite constant and with the increase of the skew angle from $30^{\circ}$ to $60^{\circ}$, the capability to dissipate energy is improved with clear consequences in the increase of the equivalent viscous damping ratio, as can be seen comparing Tables 7 and 8 ).

\section{Strengthening conclusions and comparisons}

Comparing the experimental force-displacement curves, obtained for the unstrengthened and strengthened connections (Figures 16 and 17) under monotonic loading, leads to the conclusion that all the strengthening schemes improve the behavior of the unstrengthened connections. In the case of connections with $30^{\circ}$ skew angle (see Figure 16), the strengthening techniques analyzed increase the stiffness, in particular in the positive loading direction, and the maximum strength for both directions.

The elasto-plastic behavior with limited ductility evidenced by the unstrengthened connections under negative loading is substituted by full non-linear curves exhibiting high ductility of the strengthened connections. By comparing the strengthening techniques evaluated, it is possible to conclude that the less efficient (regarding maximum force and stiffness) is the tension tie. Connections strengthened with stirups and binding strip attained the same level of maximum force, yet, this later scheme has a lower ductility capacity. Strengthened connections with stirrups and internal bolt presented significant ductility in the negative direction. On the contrary, the measured force values were already decreasing when the tests on strengthened connections with binding strip were interrupted. Therefore, from the internal bolt and the binding strip, the first one is more efficient in terms of ductility capacity, providing a better seismic behavior of the connection. The effect of the strengthening schemes in the negative loading directions of the monotonic tests is obvious: the increase of the maximum force and ductility 
capacity. The benefits concerning the stiffness are not significant (the stiffness displayed by the tension ties technique is even smaller). However, the brittle behavior exhibited by unstrengthened connections disappears in all strengthened specimens. Therefore, the main profit of adding a metal device to the connections is the improvement of ductility with clear advantages in their seismic behavior. Only the binding strip showed limitations in terms of maximum displacement.

Extending the comparison to the case of connections with $60^{\circ}$ skew angle, the main conclusions still apply (see Figure 17). The more evident benefit, which is normally the main goal of a strengthening intervention, is the improvement of the connection ductility. In particular, under monotonic negative loading, the behavior of the unstrengthened connections, characterized by having a limited ductility, gives place to a full non-linear behavior with considerable ductility in the strengthened connections. The strengthening techniques evaluated do not alter the stiffness but result in an increase of the maximum force achieved in the tests in both directions, in particular, under monotonic positive loading. Between the strengthening techniques studied, the differences in the force-displacement curves are only visible under monotonic loading in the negative direction. In this case, stirrup is the more efficient (maximum load achieved), while the effects of the tension ties and the bolt are quite similar.

The improvements in the connection behavior under monotonic loading, provided by the strengthening techniques evaluated, are highlighted by the response under cyclic loading (Figure 18 and 19).

Without any strengthening device, the connection is not able to prevent failure caused by load reversals (detachment of the connected elements) even when the rafter compression stress is augmented (from 1.4 MPa to $2.5 \mathrm{MPa}$ ). The unstrengthened connections showed a very limited capability to dissipate energy. All strengthening techniques adopted were efficient in the improvement of the hysteretic behavior of the connections. Hysteretic equivalent viscous damping ratios $\left(v_{\text {eq }}\right)$ evaluated from tests results are considerable (Table 7$)$. The best results under cyclic loading were achieved when either stirrups, tension ties or bolts were used. The binding strip provided the strongest connections but the equivalent damping ratio was nearly half of the values presented by the connections strengthened with the other techniques.

In the case of $60^{\circ}$ skew angle, the strengthening techniques evaluated provide a more stable force-displacement behavior (see Figure 19). The larger cycles did not show the pinching effect observed for the unstrengthened connections and a more symmetric response was obtained.

It is important to point out that, the unstrengthened connections with $60^{\circ}$ skew angle under cyclic loading are able to retrieve the slip of the rafter compared to the step, during the imposed history, because of the high step angle. As a consequence, an extra amount of energy, which in practice does not occur, was dissipated (Table 8).

The strengthening techniques evaluated in the $60^{\circ}$ skew angle connections, when compared with the unstrengthened connections, resulted in an increase of the connection strength, energy 
dissipation and equivalent viscous damping. The results achieved by the connections strengthened with tension ties are influenced by the out-of-plane movements observed during the tests. In fact, the poor capability to prevent out-of-plane movements by the tension ties techniques is a serious disadvantage when compared with the other strengthening techniques (Figure 20).

\section{Conclusions}

Traditional timber connections, even without any strengthening device, usually have a significant moment-resisting capacity. Therefore, they should not be represented by common constraint models, like perfect hinges, but should be considered semi-rigid and friction based. The test results performed by the authors show that this capacity is function of the compression stress applied to the rafter and of the skew angle. Moreover, it is clear that the height of the rafter cross section, the friction angle [1], the existence of mortise and tenon and the moisture content [14] are also important. The experimental analysis has been of fundamental importance in order to understand the real behavior, by pointing out some important aspects like force transmission mechanisms, failure modes and guidance for appropriate strengthening solutions.

Strengthening, usually performed by addition of metal devices, is indispensable for ensuring adequate connection response, in particular, under seismic loading, or in other adverse and unpredictable loading conditions. All strengthening techniques analyzed result in an important increase of the equivalent viscous damping ratio, higher strength and significant improvement of the ductility. The energy dissipation becomes more significant as more stable cycles are achieved. From the strengthening techniques evaluated, the insertion of one bolt across the connection axis or metal stirrups positioned at the two sides of the connection, bolted to the timber elements, resulted in the most favourable results.

\section{References}

[1] Parisi, M. and Piazza, M. (2000). Mechanics of plain and retrofitted traditional timber connections. Journal of Structural Engineering, 126(12):1395-1403.

[2] Piazza, M. and Del Senno, M. (2001). Proposals and criteria for the preliminary evaluation, the design and the execution of works on ancient load bearing timber structures. In Wooden Handwork/Wooden Carpentry: European Restoration Sites, pages 263-277, Paris, France. Elsevier.

[3] Branco, J. (2008). Influence of the joints stiffness in the monotonic and cyclic behaviour of traditional timber trusses. Assessment of the efficacy of different strengthening techniques. PhD thesis, University of Minho and University of Trento.

[4] Candelpergher, L. (1999). Sperimentazione, modellazione numerica e caratterizzazione sintetica del comportamento di collegamenti lignei tradizionali con elementi metallici. Master's thesis, Universit'a Degli Studi di Trento. In Italian. 
[5] Branco, J., Cruz, P., Varum, H., and Piazza, M. (2005b). Portuguese traditional timber trusses. Static and dynamic behaviour. Technical Report E-19/05, Guimarães, Portugal. In Portuguese.

[6] Branco, J., Santos, A., and Cruz, P. (2008). Traditional timber trusses: evolution, behaviour and strengthening with composites. Revista Portuguesa de Engenharia de Estruturas, 3:518. In Portuguese.

[7] Branco, J., Cruz, P., Piazza, M., and Varum, H. (2005a). Experimental analysis of birdsmouth joints. Technical Report E-11/05, Guimarães, Portugal.

[8] NP 4305 (1995). Structural maritime pine sawn timber - Visual grading. Instituto Português da Qualidade. In Portuguese.

[9] EN 1912 (2004). Structural timber - Strength classes - Assignment of visual grades and species. European Committee for Standardization.

[10] EN 408 (2003). Timber structures. Structural timber and glued laminated timber. Determination of some physical and mechanical properties. European Committee for Standardization.

[11] LNEC (1997). Madeira para construção - Pinho bravo para estruturas. Ficha M2.

[12] Dolan, J. (1994). Timber structures in seismic regions. Materials and Structures, 27(167):157-184.

[13] EN 12512 (2001). Timber structures - Test methods - Cyclic testing of joints made with mechanical fasteners. European Committee for Standardization.

[14] Palma, P. and Cruz, H. (2007). Mechanical behaviour of traditional timber carpentry joints in service conditions - results of monotonic tests. In From material to Structure - Mechanical behaviour and failures of the timber structures XVI International Symposium, Venice, Italy. ICOMOS IWC. 
Table 1: Tests performed on full-scale traditional timber connections.

\begin{tabular}{|c|c|c|c|c|}
\hline Specimen & $\begin{array}{l}\text { Loading } \\
\text { Method }\end{array}$ & $\begin{array}{c}\text { Type of } \\
\text { connection }\end{array}$ & $\begin{array}{l}\text { Compression } \\
\text { stress }(\mathrm{MPa})\end{array}$ & $\begin{array}{l}\text { Skew } \\
\text { angle }\end{array}$ \\
\hline $\mathrm{U} 3-1.4-1,2,3$ & Monot. + & & & \multirow{18}{*}{$30^{\circ}$} \\
\hline $\mathrm{U} 3-1.4-4,5,6$ & Monot. - & Unstrengthened & 1.4 & \\
\hline $\mathrm{U} 3-1.4-7,8,9$ & Cyclic & & & \\
\hline $\mathrm{U} 3-2.5-1,2,3$ & Monot. + & & & \\
\hline $\mathrm{U} 3-2.5-4,5,6$ & Monot. - & Unstrengthened & 2.5 & \\
\hline $\mathrm{U} 3-2.5-7,8,9$ & Cyclic & & & \\
\hline $\mathrm{S} 3-1,2,3$ & Monot. + & & \multirow{12}{*}{1.4} & \\
\hline $\mathrm{S} 3-4,5,6$ & Monot. - & Stirrup & & \\
\hline $\mathrm{S} 3-7,8,9$ & Cyclic & & & \\
\hline $\mathrm{B} 3-1,2,3$ & Monot. + & \multirow{3}{*}{ Bolt } & & \\
\hline $\mathrm{B} 3-4,5,6$ & Monot. - & & & \\
\hline $\mathrm{B} 3-7,8,9$ & Cyclic & & & \\
\hline $\mathrm{BS} 3-1,2,3$ & Monot. + & \multirow{3}{*}{ Binding strip } & & \\
\hline $\mathrm{BS} 3-4,5,6$ & Monot. - & & & \\
\hline $\mathrm{BS} 3-7,8,9$ & Cyclic & & & \\
\hline TT3-1,2,3 & Monot. + & \multirow{3}{*}{ Tension Ties } & & \\
\hline TT $3-4,5,6$ & Monot. - & & & \\
\hline ТT $3-7,8,9$ & Cyclic & & & \\
\hline $\mathrm{U} 6-1.4-1,2,3$ & Monot. + & \multirow{3}{*}{ Unstrengthened } & \multirow{3}{*}{1.4} & \multirow{15}{*}{$60^{\circ}$} \\
\hline $\mathrm{U} 6-1.4-4,5,6$ & Monot. - & & & \\
\hline $\mathrm{U} 6-1.4-7,8,9$ & Cyclic & & & \\
\hline $\mathrm{U} 6-2.5-1,2,3$ & Monot. + & \multirow{3}{*}{ Unstrengthened } & \multirow{3}{*}{2.5} & \\
\hline $\mathrm{U} 6-2.5-4,5,6$ & Monot. - & & & \\
\hline $\mathrm{U} 6-2.5-7,8,9$ & Cyclic & & & \\
\hline $\mathrm{S} 6-1,2,3$ & Monot. + & \multirow{3}{*}{ Stirrup } & \multirow{9}{*}{1.4} & \\
\hline $\mathrm{S} 6-4,5,6$ & Monot. - & & & \\
\hline $\mathrm{S} 6-7,8,9$ & Cyclic & & & \\
\hline $\mathrm{B} 3-1,2,3$ & Monot. + & \multirow{3}{*}{ Bolt } & & \\
\hline $\mathrm{B} 3-4,5,6$ & Monot. - & & & \\
\hline $\mathrm{B} 3-7,8,9$ & Cyclic & & & \\
\hline TT6-1,2,3 & Monot. + & \multirow{3}{*}{ Tension Ties } & & \\
\hline TT $6-4,5,6$ & Monot. - & & & \\
\hline TT6 - 7, 8, 9 & Cyclic & & & \\
\hline
\end{tabular}

NOTE: Based on the test results obtained for $30^{\circ}$ skew angle connections, it was decided not to extended the binding strip (BSi) to the $60^{\circ}$ skew angle case. 
Table 2: Comparison between the mechanical properties for Pinus Pinaster, Ait. quality class E obtained in the test results and reported by LNEC (1997).

\begin{tabular}{cccccc}
\hline \hline Source & $\begin{array}{c}E_{\mathrm{m}} \\
(\mathrm{MPa})\end{array}$ & $\begin{array}{c}E_{0,05} \\
(\mathrm{MPa})\end{array}$ & $\begin{array}{c}f_{\mathrm{m}} \\
(\mathrm{MPa})\end{array}$ & $\begin{array}{c}f_{\mathrm{c}, 0} \\
(\mathrm{MPa})\end{array}$ & $\begin{array}{c}f_{\mathrm{c}, 90} \\
(\mathrm{MPa})\end{array}$ \\
\hline LNEC (1997) & 12000 & 8000 & 18 & 18 & 6.9 \\
Test results & 11156 & 7992 & 25 & 20 & 4.0 \\
\hline \hline
\end{tabular}

Table 3: Monotonic tests results of strengthened connection with binding strip.

\begin{tabular}{|c|c|c|c|c|c|c|}
\hline \multirow{2}{*}{ Specimen } & \multirow{2}{*}{$\begin{array}{c}\sigma_{\mathrm{c}} \\
(\mathrm{MPa})\end{array}$} & \multirow{2}{*}{$\begin{array}{c}d_{\mathrm{e}} \\
(\mathrm{mm})\end{array}$} & \multirow{2}{*}{$\begin{array}{l}F_{\max } \\
(\mathrm{kN})\end{array}$} & \multicolumn{3}{|c|}{ Stiffness $(\mathrm{kN} / \mathrm{mm}) \times 10^{3}$} \\
\hline & & & & Regression & $F_{\mathrm{e}} / d_{\mathrm{e}}$ & $F_{\mathrm{e}}^{50 \%} / d_{\mathrm{e}}^{50 \%}$ \\
\hline BS3-1 & \multirow{3}{*}{1.4} & 4.00 & 17.01 & 1629 & 1489 & 1608 \\
\hline BS3-2 & & 4.80 & 15.82 & 1430 & 1306 & 1367 \\
\hline \multirow[t]{3}{*}{ BS3-3 } & & 4.30 & 18.81 & 1357 & 1252 & 1384 \\
\hline & Mean & 4.37 & 17.21 & 1472 & 1349 & 1453 \\
\hline & $\mathrm{CoV}$ & 9.25 & 8.75 & 9.56 & 9.21 & 9.26 \\
\hline BS3-4 & \multirow{3}{*}{1.4} & -7.00 & 19.10 & 1583 & 1452 & 1634 \\
\hline BS3-5 & & -5.00 & -20.00 & 1809 & 1796 & 1778 \\
\hline \multirow[t]{3}{*}{ BS3-6 } & & 7.00 & -18.81 & 1428 & 1239 & 1194 \\
\hline & Mean & -6.33 & -19.30 & 1607 & 1496 & 1535 \\
\hline & $\mathrm{CoV}$ & 18.23 & 3.21 & 11.93 & 18.79 & 19.82 \\
\hline
\end{tabular}

Table 4: Monotonic tests results of strengthened connections with stirrups.

\begin{tabular}{ccccccc}
\hline \hline \multirow{2}{*}{$\begin{array}{c}\text { Skew } \\
\text { angle }\end{array}$} & \multirow{2}{*}{$\sigma_{\mathrm{c}}$} & $d_{\mathrm{e}}$ & $F_{\max }$ & \multicolumn{3}{c}{ Stiffness $(\mathrm{kN} / \mathrm{mm}) \times 10^{3}$} \\
\cline { 5 - 7 } & $(\mathrm{MPa})$ & $(\mathrm{mm})$ & $(\mathrm{kN})$ & Regression & $F_{\mathrm{e}} / d_{\mathrm{e}}$ & $F_{\mathrm{e}}^{50 \%} / d_{\mathrm{e}}^{50 \%}$ \\
\hline \multirow{2}{*}{$30^{\circ}$} & \multirow{2}{*}{1.4} & 5.62 & 16.48 & 1517 & 1312 & 1239 \\
& & -5.79 & -15.34 & 1428 & 1257 & 1310 \\
\hline \multirow{2}{*}{$60^{\circ}$} & \multirow{2}{*}{1.4} & 18.71 & 9.23 & 377 & 360 & 356 \\
& & -8.51 & -9.38 & 526 & 546 & 580 \\
\hline \hline
\end{tabular}


Table 5: Monotonic tests results of strengthened connection with bolts.

\begin{tabular}{ccccccc}
\hline \hline \multirow{2}{*}{$\begin{array}{c}\text { Skew } \\
\text { angle }\end{array}$} & \multirow{2}{*}{$\sigma_{\mathrm{c}}$} & $d_{\mathrm{e}}$ & $F_{\max }$ & \multicolumn{3}{c}{ Stiffness $(\mathrm{kN} / \mathrm{mm}) \times 10^{3}$} \\
\cline { 5 - 7 } & $(\mathrm{MPa})$ & $(\mathrm{mm})$ & & Regression & $F_{\mathrm{e}} / d_{\mathrm{e}}$ & $F_{\mathrm{e}}^{50 \%} / d_{\mathrm{e}}^{50 \%}$ \\
\hline \multirow{2}{*}{$30^{\circ}$} & \multirow{2}{*}{1.4} & 4.94 & 13.83 & 1468 & 1381 & 1459 \\
& & -7.829 & -22.41 & 1488 & 1387 & 1409 \\
\hline \multirow{2}{*}{$60^{\circ}$} & \multirow{2}{*}{1.4} & 10.92 & 7.85 & 442 & 446 & 465 \\
& & -5.22 & -7.08 & 623 & 657 & 838 \\
\hline \hline
\end{tabular}

Table 6: Monotonic tests results of strengthened connection with tension ties.

\begin{tabular}{ccccccc}
\hline \hline \multirow{2}{*}{$\begin{array}{c}\text { Skew } \\
\text { angle }\end{array}$} & \multirow{2}{*}{$\sigma_{\mathrm{c}}$} & $d_{\mathrm{e}}$ & $F_{\max }$ & \multicolumn{3}{c}{ Stiffness $(\mathrm{kN} / \mathrm{mm}) \times 10^{3}$} \\
\cline { 5 - 7 } & $(\mathrm{mm})$ & $(\mathrm{kN})$ & Regression & $F_{\mathrm{e}} / d_{\mathrm{e}}$ & $F_{\mathrm{e}}^{50 \%} / d_{\mathrm{e}}^{50 \%}$ \\
\hline \multirow{2}{*}{$30^{\circ}$} & \multirow{2}{*}{1.4} & 4.91 & 7.65 & 556 & 555 & 570 \\
& & -4.91 & -11.26 & 610 & 651 & 749 \\
\hline \multirow{2}{*}{$60^{\circ}$} & \multirow{2}{*}{1.4} & 9.72 & 7.91 & 461 & 471 & 495 \\
& & -6.71 & -6.08 & 639 & 664 & 710 \\
\hline \hline
\end{tabular}

Table 7: Cyclic tests results of $30^{\circ}$ skew angle connections.

\begin{tabular}{ccccccc}
\hline \hline Connection & $\begin{array}{c}d_{\max }^{+} \\
(\mathrm{mm})\end{array}$ & $\begin{array}{c}d_{\max }^{-} \\
(\mathrm{mm})\end{array}$ & $\begin{array}{c}F_{\max }^{+} \\
(\mathrm{kN})\end{array}$ & $\begin{array}{c}F_{\max }^{-} \\
(\mathrm{kN})\end{array}$ & $\begin{array}{c}\text { Dissipated } \\
\text { Energy }(\mathrm{kJ})\end{array}$ & $\begin{array}{c}V_{\mathrm{eq}} \\
(\%)\end{array}$ \\
\hline Unstrengthened (U) & 16.49 & -15.83 & 6.20 & -11.57 & 230 & 2.45 \\
\hline Tension ties (TT) & 4.91 & -4.91 & 7.65 & -11.26 & 554 & 12.83 \\
Bolt (B) & 13.30 & -35.30 & 15.29 & -21.08 & 1877 & 11.28 \\
Stirrup (S) & 28.68 & -21.75 & 18.09 & -15.60 & 1859 & 14.57 \\
Binding strip (BS) & 18.38 & -39.63 & 23.38 & -25.47 & 2874 & 6.85 \\
\hline \hline
\end{tabular}

Table 8: Cyclic tests results of $60^{\circ}$ skew angle connections.

\begin{tabular}{ccccccc}
\hline \hline Connection & $\begin{array}{c}d_{\max }^{+} \\
(\mathrm{mm})\end{array}$ & $\begin{array}{c}d_{\max }^{-} \\
(\mathrm{mm})\end{array}$ & $\begin{array}{c}F_{\max }^{+} \\
(\mathrm{kN})\end{array}$ & $\begin{array}{c}F_{\max }^{-} \\
(\mathrm{kN})\end{array}$ & $\begin{array}{c}\text { Dissipated } \\
\text { Energy }(\mathrm{kJ})\end{array}$ & $\begin{array}{c}V_{\mathrm{eq}} \\
(\%)\end{array}$ \\
\hline Unstrengthened (U) & 33.36 & -33.36 & 4.06 & -5.27 & 809 & 14.23 \\
\hline Tension ties (TT) & 32.80 & -32.96 & 8.13 & -5.50 & 990 & 37.82 \\
Bolt (B) & 32.55 & -32.67 & 7.36 & -6.72 & 762 & 24.38 \\
Stirrup (S) & 27.16 & -27.28 & 7.09 & -7.21 & 1080 & 35.77 \\
\hline \hline
\end{tabular}




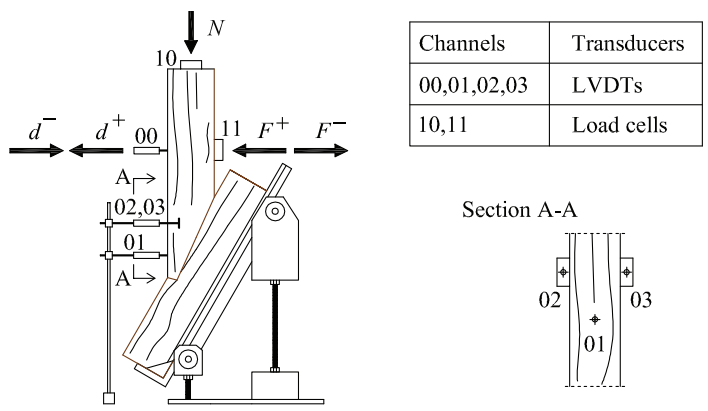

Figure 1: Testing apparatus and instrumentation layout. 


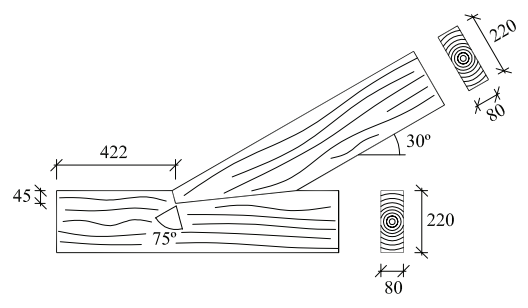

(a) $30^{\circ}$ skew angle

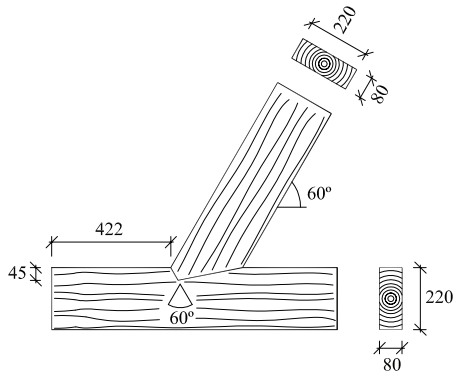

(b) $60^{\circ}$ skew angle

Figure 2: Connections geometry (mm). 


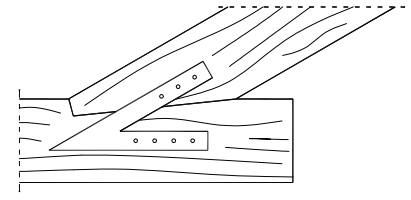

(a) Stirrup

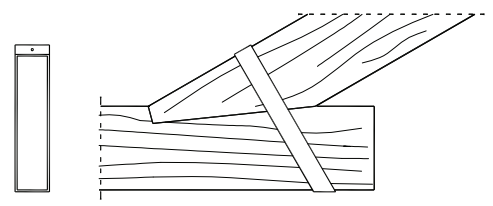

(c) Binding strip

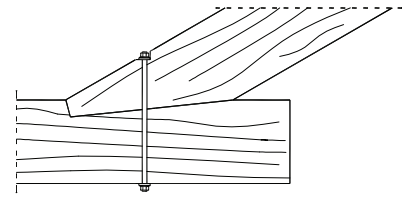

(b) Internal bolt

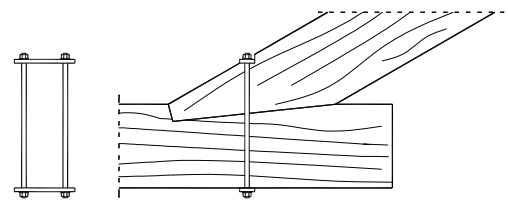

(d) Tension ties

Figure 3: Traditional strengtheneing techniques evaluated. 


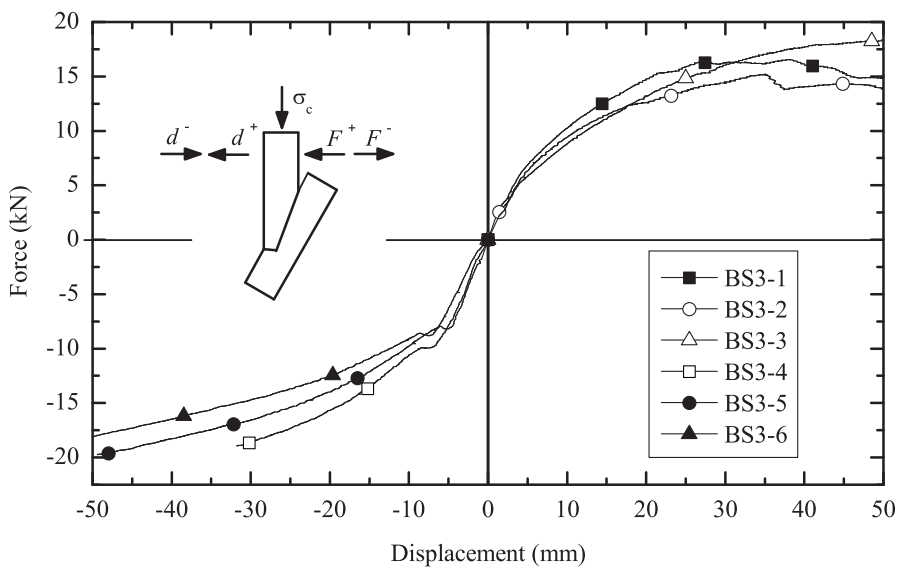

Figure 4: Force-displacement curves for $30^{\circ}$ skew angle strengthened connections with binding strip under monotonic loading. 


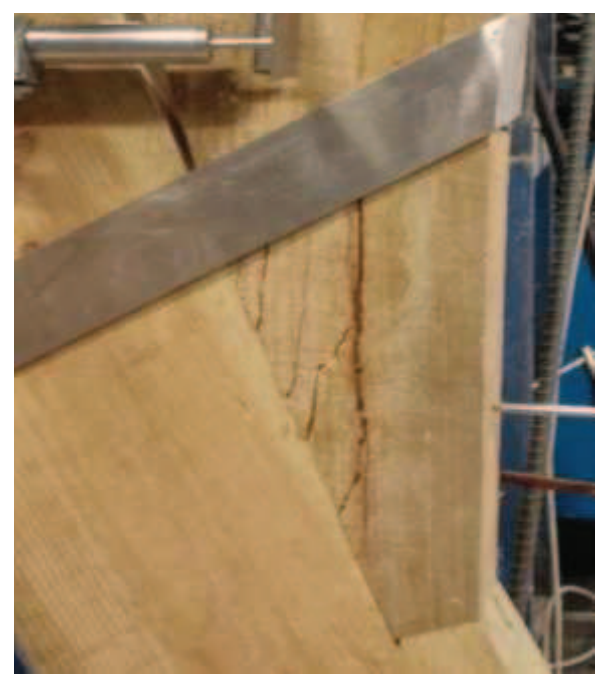

Figure 5: Damage observed in the $30^{\circ}$ skew angle strengthened connections with binding strip under monotonic loading in positive direction. 


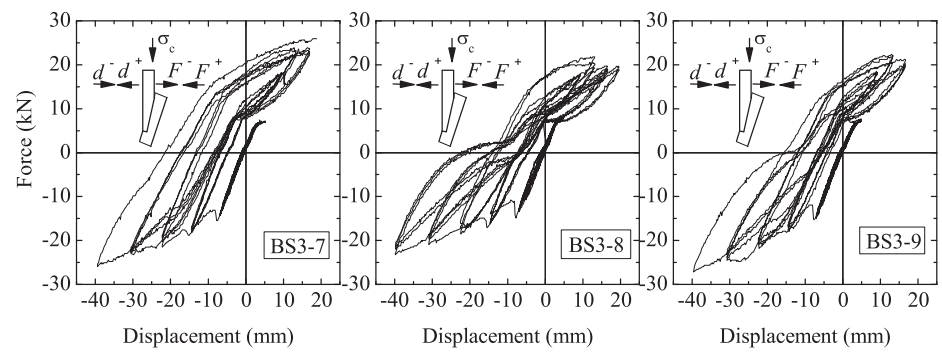

Figure 6: Force-displacement loops for $30^{\circ}$ skew angle strengthened connections with binding strip under cyclic loading. 


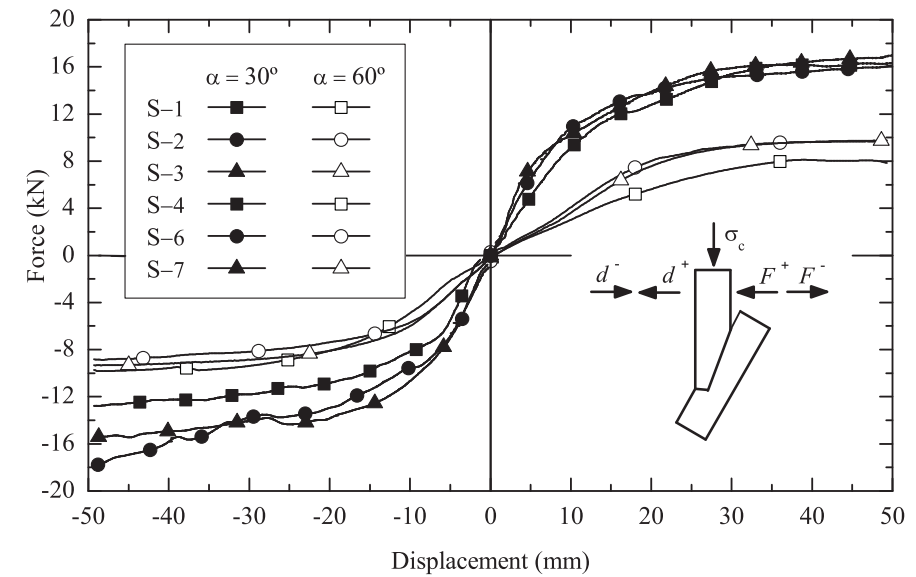

Figure 7: Force-displacement curves of stirrup strengthened connections with $30^{\circ}$ and $60^{\circ}$ skew angles under monotonic loading. 


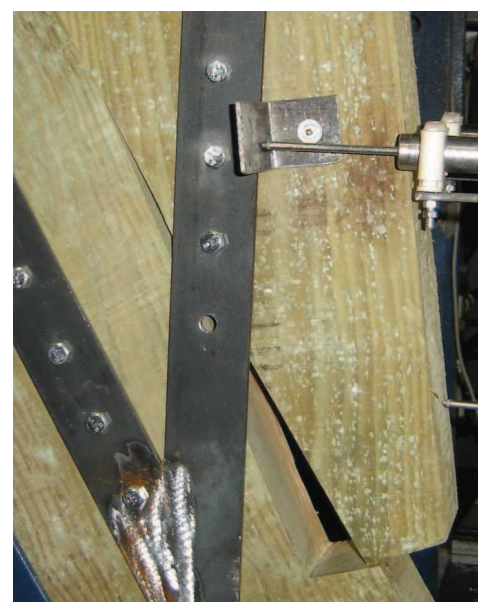

(a) Negative loading direction

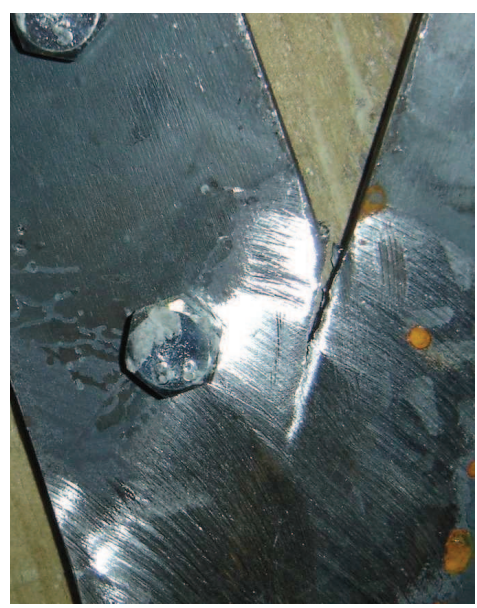

(b) Positive loading direction

Figure 8: Final deformation of the strengthened connections under monotonic loading (30 skew angle). 

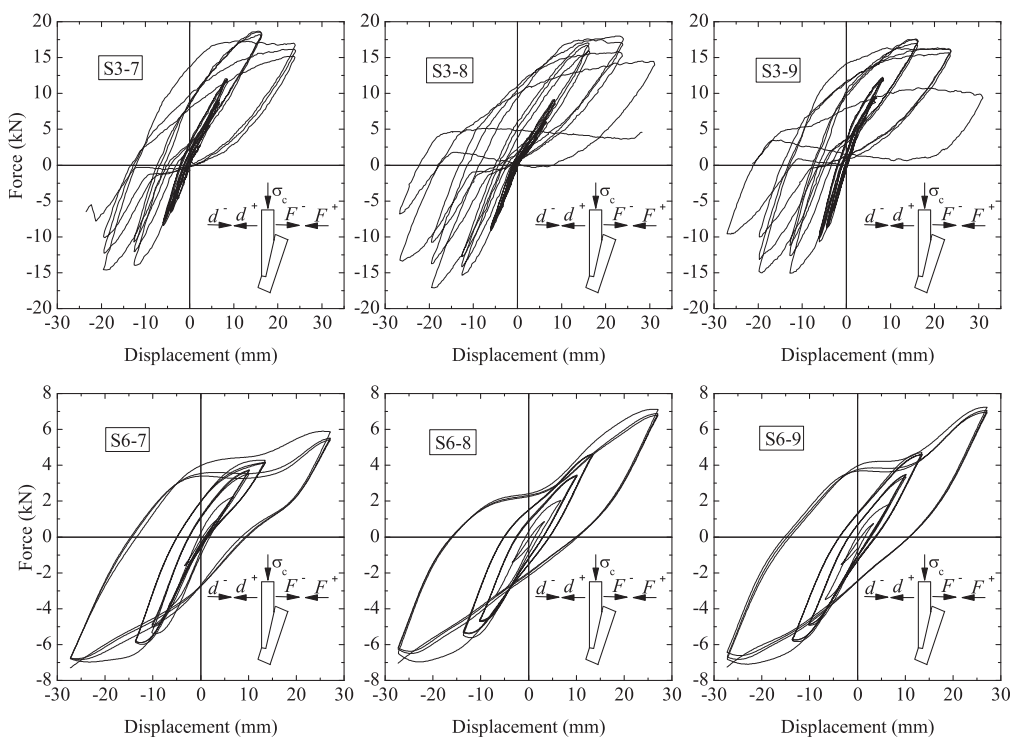

Figure 9: Force-displacement loops for stirrup strengthened connections with $30^{\circ}$ and $60^{\circ}$ skew angle under cyclic loading. 


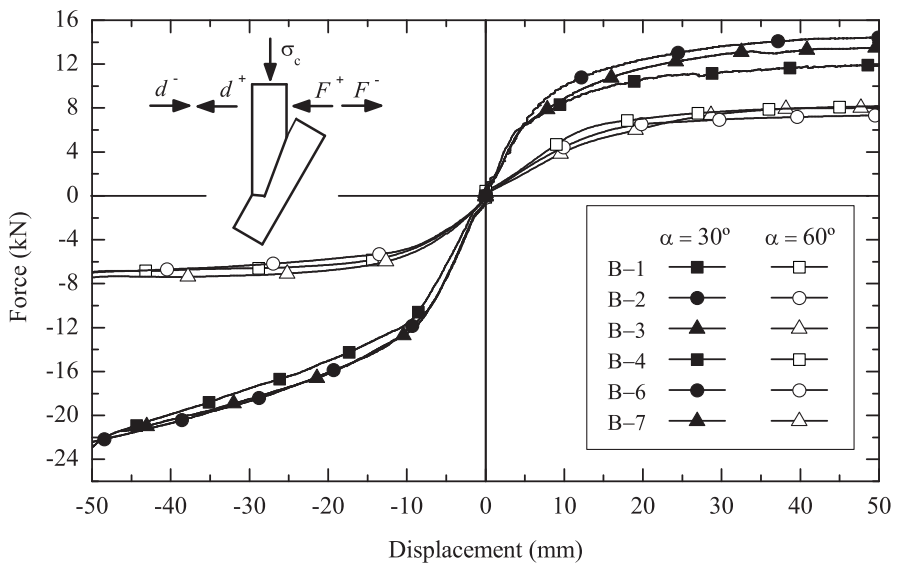

Figure 10: Force-displacement curves of bolt strengthened connections with $30^{\circ}$ and $60^{\circ}$ skew angles under monotonic loading. 


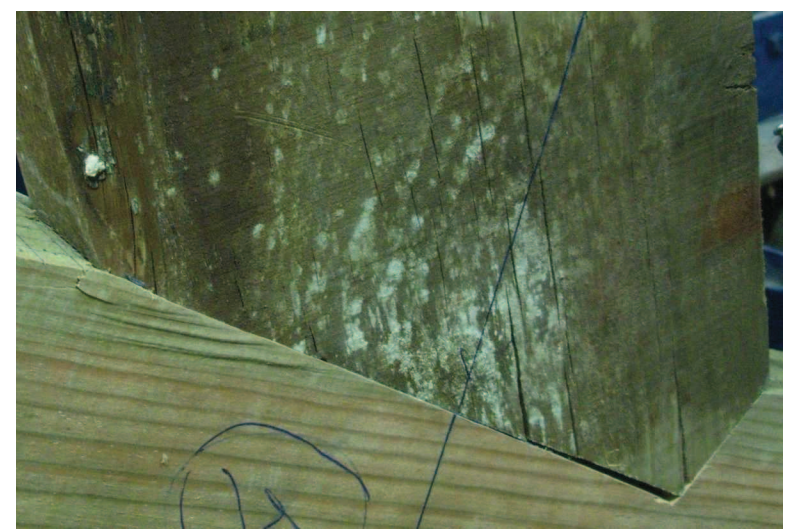

Figure 11: Local compression perpendicular to the grain. 

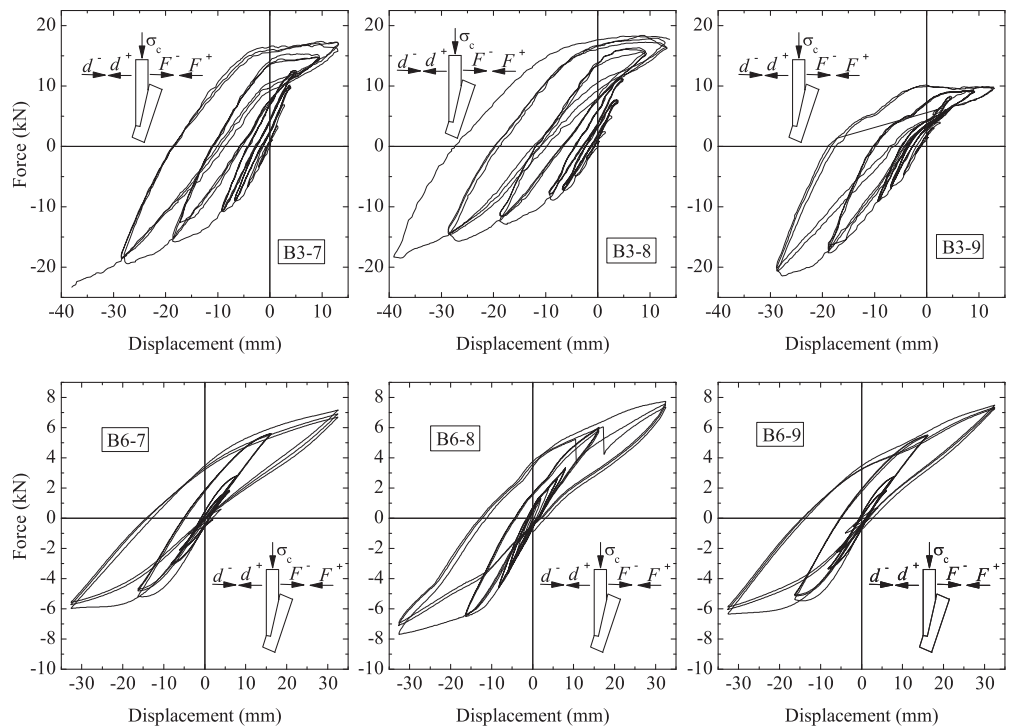

Figure 12: Force-displacement loops for bolt strengthened connections with $30^{\circ}$ and $60^{\circ}$ skew angle under cyclic loading. 


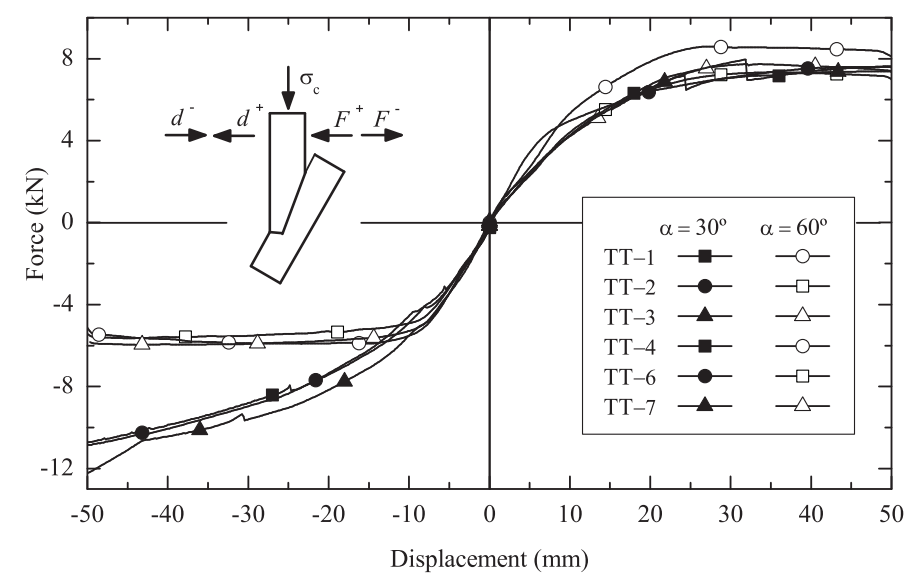

Figure 13: Force-displacement curves of tension ties strengthened connections with $30^{\circ}$ and $60^{\circ}$ skew angles under monotonic loading. 


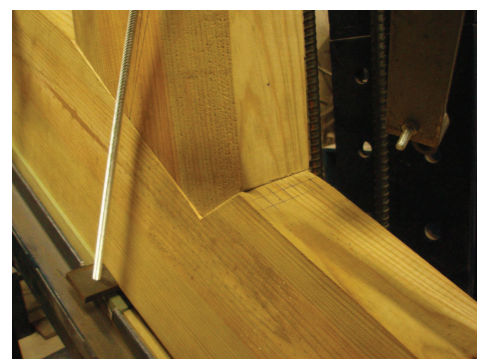

(a) Positive loading direction

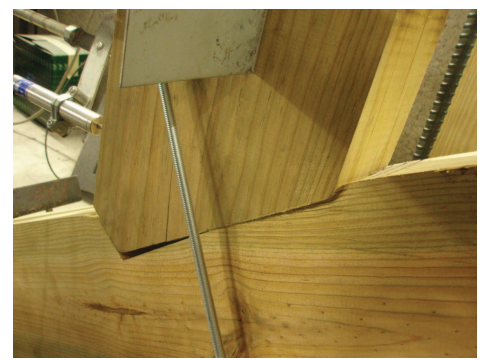

(b) Negative loading direction

Figure 14: Damages observed in the $60^{\circ}$ skew angle strengthened connections with tension ties under monotonic loading. 

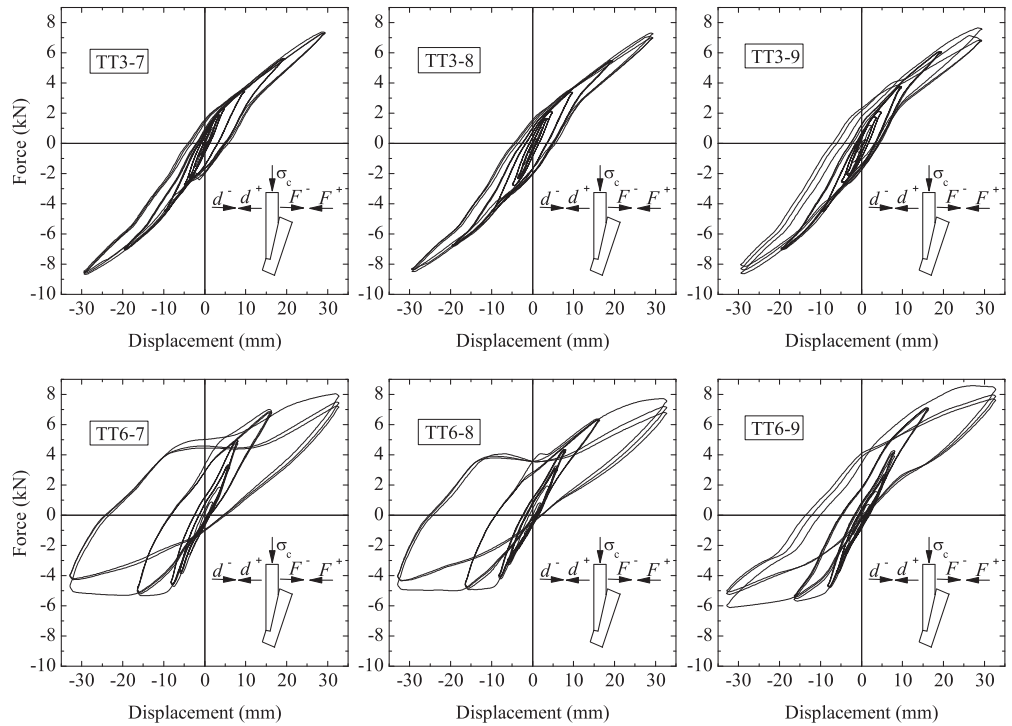

Figure 15: Force-displacement loops for tension ties strengthened connections with $30^{\circ}$ and $60^{\circ}$ skew angle under cyclic loading. 


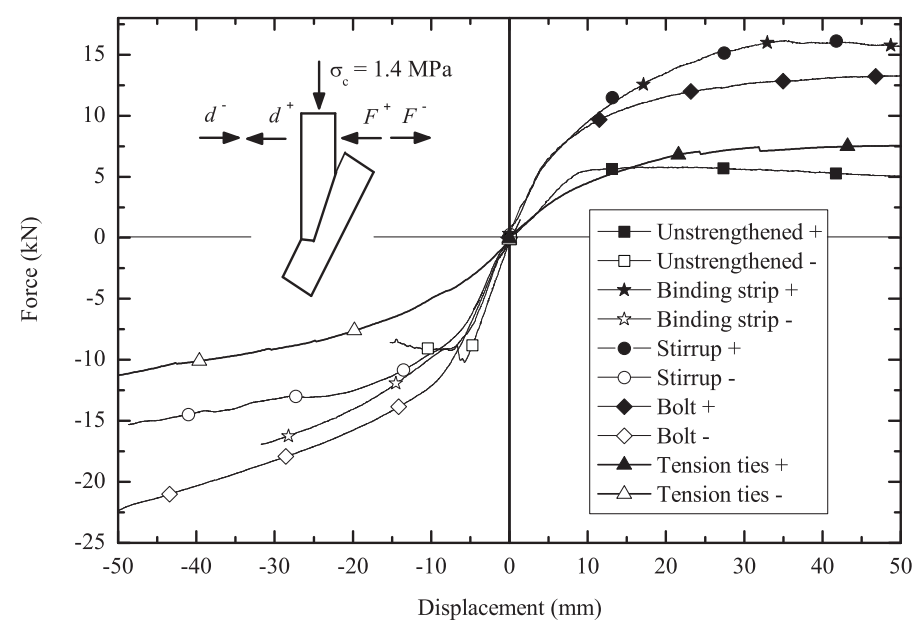

Figure 16: Force-displacement average curves for unstrengthened and strengthened connections with $30^{\circ}$ skew angle under monotonic loading. 


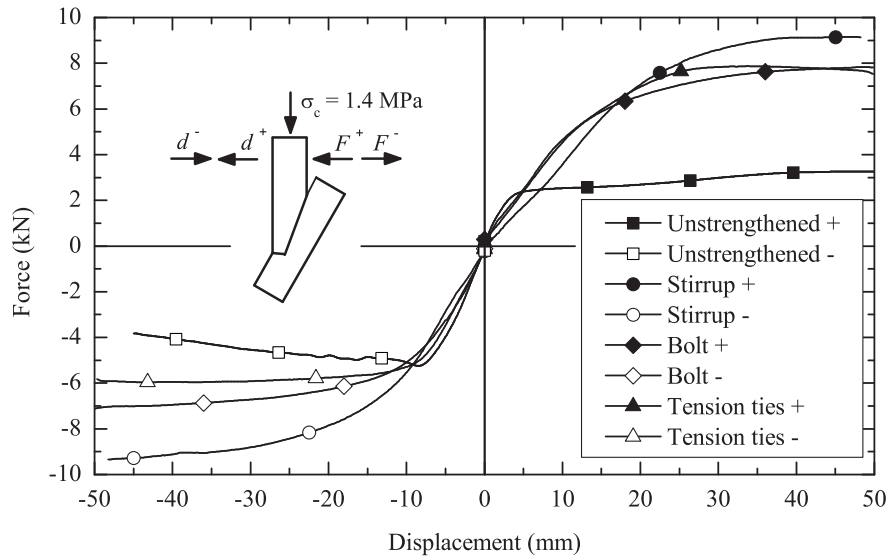

Figure 17: Force-displacement average curves for unstrengthened and strengthened connections with $60^{\circ}$ skew angle under monotonic loading. 

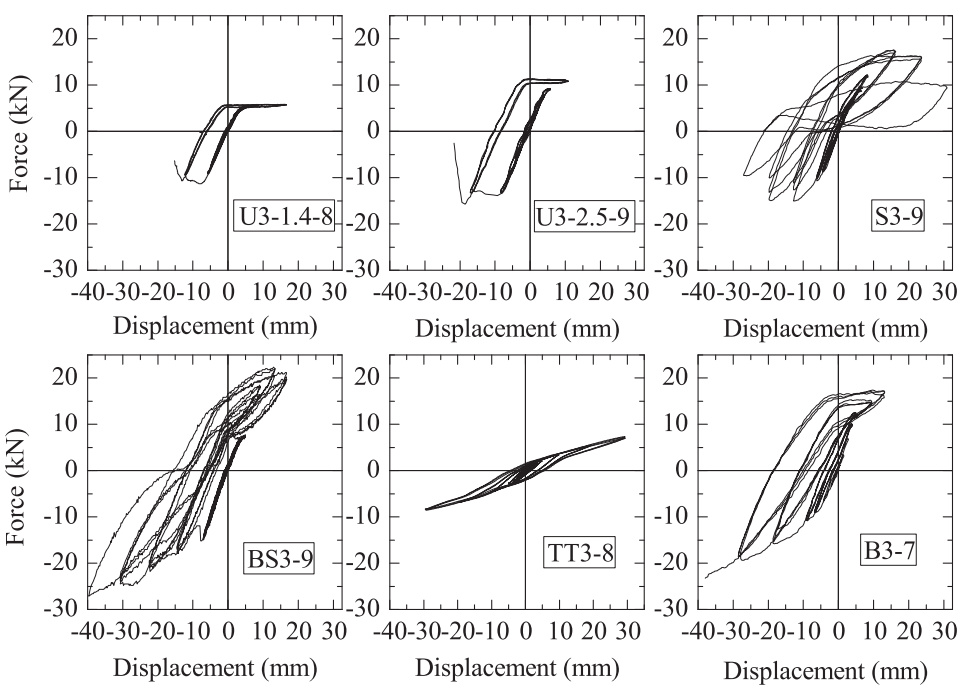

Figure 18: Force-displacement loops for unstrengthened and strengthened connections with $30^{\circ}$ skew angle under cyclic loading. U - unstrengthened, S stirrup, BS - Binding strip, TT - Tension ties and B - Bolt. 

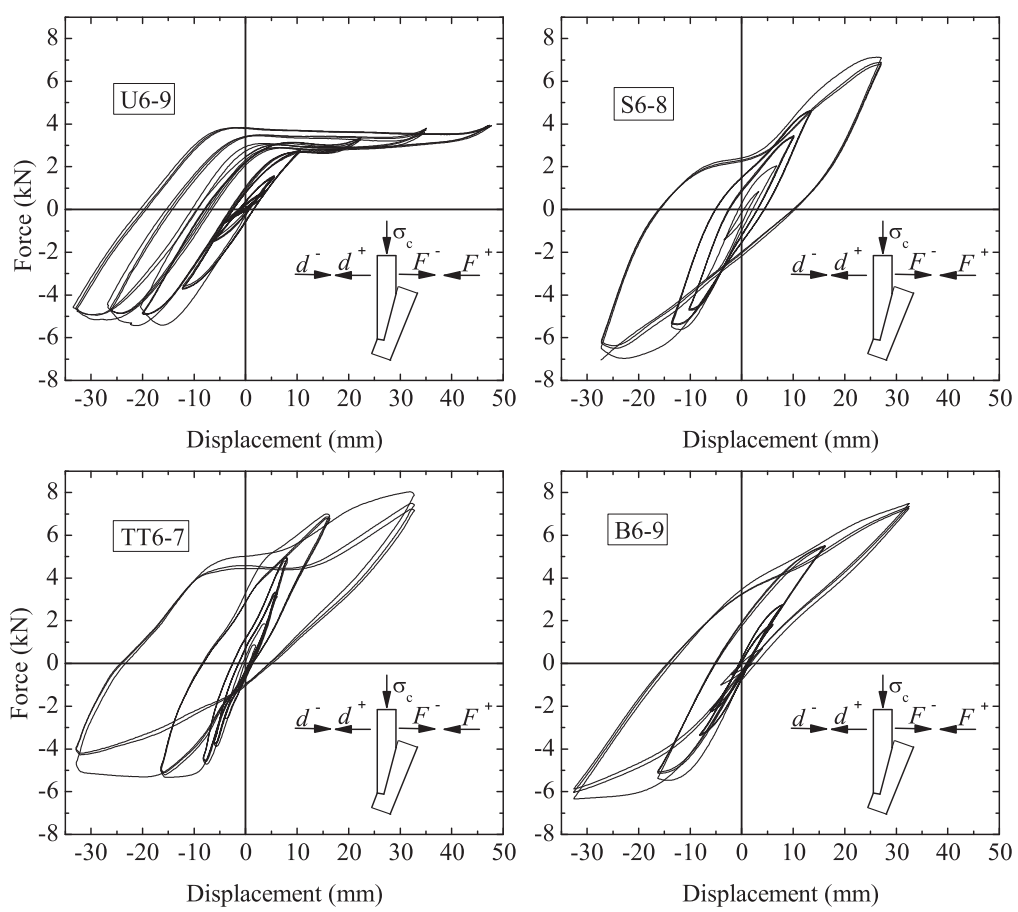

Figure 19: Force-displacement loops for unstrengthened and strengthened connections with $60^{\circ}$ skew angle under cyclic loading. U - unstrengthened, S stirrup, TT - Tension ties and B - Bolt. 


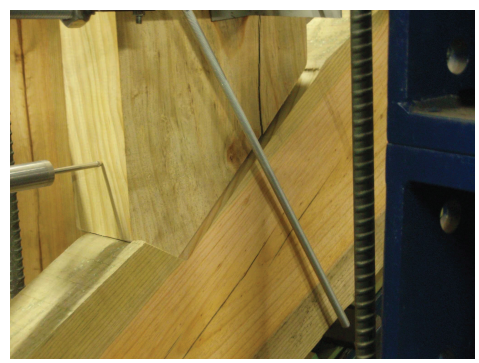

(a) Positive loading direction

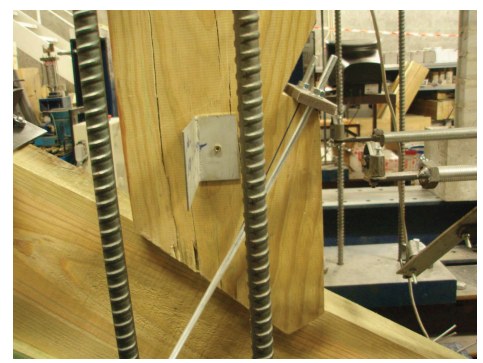

(b) Cyclic test

Figure 20: Out-of-plane movements detected in the $60^{\circ}$ skew angle connections strengthened with tension ties. 